\title{
Recurrent Lumbar Disc Herniation in Pregnant Patient: A Case Report
}

\author{
Mehmet Resid Onen ${ }^{1 *}$, Evren Yuvruk ${ }^{1}$, Mehmet Erdem Akcay ${ }^{2}$ and Sait Naderi ${ }^{1}$ \\ ${ }^{1}$ Department of Neurosurgery, Umraniye Teaching and Research hospital, Istanbul, Turkey \\ ${ }^{2}$ Department of Anesthesiology, Umraniye Teaching and Research hospital, Istanbul, Turkey
}

\begin{abstract}
Introduction: Lower back and leg pain are frequently seen pathologies in pregnancy. However, a small proportion of these complaints develop in association with lumbar disc hernias. Due to maternal and fetal factors, diagnosis and treatment during pregnancy has to be different than for non-pregnant patients.
\end{abstract}

Methods: A 36 year old, 28-week pregnant patient presented with ever-increasing pain in the right leg, lower back, and reduced power in the extensor hallucis longus. The patient had undergone surgery at another clinic about 2.5 years ago because of right L4-5 disc herniation. Therefore the patient was evaluated by lumbar magnetic resonance images [MRI]. The MRI determined the right L4-5 recurrent disc herniation.

Results: The patient underwent successful surgery in the lateral decubitus position under general anesthesia. No complications developed in mother or fetus.

Conclusion: Recurrent lumbar disc herniation during pregnancy has not been reported. A lumbar micro-discectomy procedure for a pregnant patient resulted in a successful clinical outcome.

Keywords: Pregnancy; Herniated lumbar disc; Recurrent lumbar disc herniation; Magnetic resonance imaging

\section{Introduction}

Low back and radicular pain during pregnancy are seen in approximately half of all pregnant females [1]. Although lumbar disc herniation (LDH) accompanied by radiculopathy and low back pain occurs frequently, there are very few published cases of LDH surgery in pregnancy [1-8]. The most important reason for this disproportionality is the difficulty of surgical practice. Problems such as possible damages to the fetus, problems in selection of the appropriate surgery position and the effects of the anesthetic agents to the fetus lead to delays in decision-making for surgery [3-5]. Similarly, treatment may be delayed as far as possible as potential damage to the fetus would affect not only the newborn but also the parents.

The aim of this study was to present the results of surgery applied because of recurrent LDH in a patient in the 3 rd trimester of pregnancy.

\section{Case Report}

A 36-year old, 28-week pregnant patient presented with ever increasing pain in the right leg and lower back. The family doctor had given treatment of 2 weeks bed rest and paracetamol. With an increase in radicular pain especially in the right leg, and development of reduced power in the extensor hallucis longus (EHL), she was referred to the neurosurgery outpatient clinic. During this period, the patient experienced sleep loss, limited movement and was confined to bed

Previously, the patient had undergone surgery at another clinic about 2.5 years ago because of right $\mathrm{L}_{4-5}$ disc herniation.

Until a month ago, the patient who had no complaints about disk herniation was treated because of back and leg pain at the physical and rehabilitation clinic. During this period, the patient was on bed rest and was treated with medication. However, $\mathrm{L}_{4-5}$ disc herniation was determined in the patient by lumbar magnetic resonance images (MRI) with the increase of complaints and the development of neurologic deficit.

When the patient consulted our clinic, hypoesthesia was detected in the right $\mathrm{L}_{5}$ dermatome in the physical examination. The straight leg raise test was positive at $30^{\circ}$. Right EHL power was found to be $2 / 5$, and right tibialis anterior muscle power was found to be $3 / 5$. The visual analog scale (VAS) was 9.

In the lumbar MRI of the patient, a disc hernia extrusion compressing the right $\mathrm{L}_{5}$ root was determined on $\mathrm{T} 2$ isointense. A right $\mathrm{L}_{4}$ laminectomy defect was also seen (Figure 1). Since the patient was pregnant, gadolinium, which is used for elimination and exclusion when making a definitive diagnosis in most recurrent disc cases, was not applied.

Surgical treatment was recommended because of the progressive increasing neurological deficit and as the pain had not responded to conservative treatment.

\section{Surgical technique}

Anesthesia induction was applied with $2 \mathrm{mg} / \mathrm{kg}$ propofol and 0.5 $\mathrm{mg} / \mathrm{kg}$ rocoronium intravenous, following $100 \%$ oxygen with 5-minute pre-oxygenation. Anesthesia maintenance at 50\% $\mathrm{O}_{2}-50 \%$ air and $5 \%$ desflurane was ensured by remifentanil infusion in the titration range of $0.05-0.2 \mu \mathrm{g} / \mathrm{kg} /$ minute. During the surgery, no neuromuscular blocker antagonist was used. A gynecology specialist monitored fetal heartbeats and fetal movements preoperatively, intraoperatively and postoperatively.

After intubation, the patient was laid in the lateral decubitus position with the right side uppermost (Figure 2) with the spinous process levels showing about $2-3 \mathrm{~cm}$ of shift with the skin incision line. As it was not possible to check the level by preoperative fluoroscopy, the sacrum was felt manually and the incision was extended to $\mathrm{L}_{5}-\mathrm{S}_{1}$

*Corresponding author: Mehmet Resid Onen, Chief Assistant, Umraniye Teaching and Research hospital, 34760 Istanbul, Turkey, Tel: +90 505 3540421; E-mail: mresid@gmail.com

Received January 09, 2015; Accepted January 20, 2015; Published January 22 2015

Citation: Onen MR, Yuvruk E, Akcay ME, Naderi S (2015) Recurrent Lumbar Disc Herniation in Pregnant Patient: A Case Report. J Spine 4: 207. doi: 10.4172/2165-7939.1000207

Copyright: $\odot 2015$ Onen MR, et al. This is an open-access article distributed under the terms of the Creative Commons Attribution License, which permits unrestricted use, distribution, and reproduction in any medium, provided the original author and source are credited. 


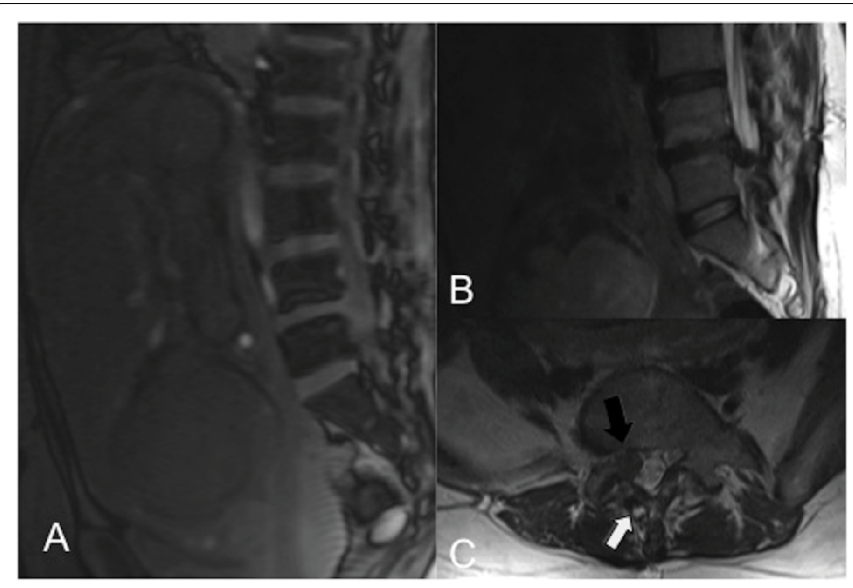

Figure 1: Lumbar spinal MRI images: (A) Fetus on the sagittal T1-weighted images, (B) Large disc fragment and fetus on the sagittal T2-weighted images, (C) Disc fragment (black arrow) and laminectomy defect (white arrow) in the right L4-5 extrusion on the axial T2-weighted images.

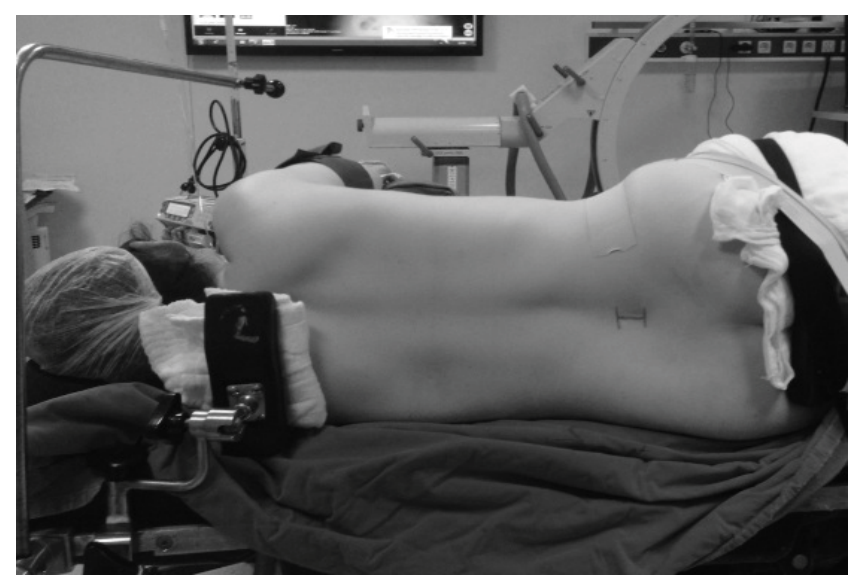

Figure 2: Lumbar micro-discectomy preparation in the left lateral decubitus position.

level. An automatic retractor for micro-discectomy was placed at $\mathrm{L}_{4}$ then partial hamilaminectomy was extended laterally and upwards. The $\mathrm{L}_{5}$ root was found and decompressed, the extruded disc material attached to the root and dura was removed. Entering the $\mathrm{L}_{4-5}$ space completed Discectomy.

Fetal parameters were re-evaluated at the postoperative 1st hour. The patient was mobilized at the 6th hour without support. The patient was discharged on the 2 nd day with complete recovery of radicular pain and no neurodeficit. But the patient still had back pain less severe than before.

\section{Discussion}

In the 1970s, De Palma stated that two basic factors in particular cause LDH in the pregnancy; the first is the extra mechanical stress added to the mother's spine because of the carriage of the fetus, and the second is the ligamentous laxity that becomes more evident towards the end of the pregnancy [2].

The relationship between the number of pregnancies and acute lower back pain attacks was published by Frymoyer et al. [9] in a study which demonstrated that lower back pain attacks in pregnant women increased considerably compared to the non-pregnant population, and attack frequency increased in direct proportion to an increase in the number of pregnancies [2,3]. The age of pregnancy has increased in developed communities from the mid-twenties to the mid-thirties, so has there been an increase in the occurrence of mechanical lower back problems in pregnancy [1]. The case presented here was 36 years old.

Theoretically MRI has biological and teratogenic effects on the fetus [10-12]. While there are no findings on this subject in humans, MRI is not advised during pregnancy, especially in the first trimester, unless absolutely necessary [10-12]. Therefore, MRI without contrast was applied to the patient in this study.

Being in the last trimester and having severe complaints and neurologic deficits MRI was applied to the patient.

Spinal surgery in pregnancy is significant in respect to both the problems that may occur because of the anesthetic agents and also the potential risks because of the surgical position. One of the most important questions which arise from surgical intervention in pregnancy is the possible teratogenic effects of anesthetic agents on the fetus. Unlike many volatile anesthetics that are in clinical use, intravenous anesthetics (such as barbiturate, ketamine, propofol) have a highly limited passage from the placenta and therefore have wide safety margins $[13,14]$. Current anesthetic devices and developments in preoperative monitoring of the systemic functions of the pregnant patient and fetus have rendered surgical interventions in pregnancy safer [13-16]. Therefore, many authors have stated that the use of general anesthesia with appropriate anesthetic agents and methods has no ill effects $[13,16]$ However, many surgeons and anesthetists prefer epidural or spinal anesthesia for cases of shorter operative duration, and general anesthesia only in longer cases [1,5].

Teratogenic effects related to anesthetic agents can be observed in the first two week of pregnancy. In the proceeding trimesters, complications such as fetal respiratory depression, supraventricular tachycardia, fetal hypotension and fetal bradycardia can develop. During the surgical period, hypoxemia, hypotension, acidosis and hyperventilation are critically important and must be treated immediately [14].

Appropriate positioning of the patient is essential in surgical interventions to be applied in pregnancy. At the beginning of the first and second trimester, the pregnant patient can be positioned in the same way as non-pregnant individuals. In the Relton-Hall frame spinal surgical Table 1, the abdominal area and sternum are under no pressure in the four-poster spinal frame system, as the patient is prone and the abdomen is supported from the iliac crests and lateral pelvis and from the lateral chest area [4-6,14]. The Wilson frame spine surgical systems are similar [15]. Difficulties arise for the lateral position in the traditional micro-discectomy approach. The left lateral decubitus position bears maternal risks with compression of the aorta-cava and in the right lateral decubitus position there can be compression of the inferior vena cava [5]. Even though there are many cases in literature of surgery in pregnancy for $\mathrm{LDH}$ and lumbar spinal stenosis, there is no case of surgery due to recurrent disc hernia [4-8].

In summary, pregnancy alone is not a contraindication for nonobstetric surgery. In symptomatic cases, MRI is the most dependable diagnostic tool in current use. In cases accompanied by neurological deficit and intense pain, when MRI shows LDH, then surgery may be indicated. A lumbar micro-discectomy procedure for a pregnant patient resulted in a successful clinical outcome. 


\section{References}

1. Brown MD, Levi AD (2001) Surgery for lumbar disc herniation during pregnancy Spine (Phila Pa 1976) 26: 440-443.

2. DePalma AF, Rothman RH (1969) Surgery of the lumbar spine. Clin Orthop Relat Res 63: 162-170.

3. Kermani HR (2003) Cauda equia syndrome in pregnancy. Arch Iranian Med 6: $146-148$

4. Hakan T (2012) Lumbar disk herniation presented with cauda equina syndrome in a pregnant woman. J Neurosci Rural Pract 3: 197-199.

5. Han IH, Kuh SU, Kim JH, Chin DK, Kim KS, et al. (2008) Clinical approach and surgical strategy for spinal diseases in pregnant women: a report of ten cases. Spine (Phila Pa 1976) 33: E614-619.

6. Mahapatra RN, Patra RK (2008) Cauda equina sydrome in pregnancy due to disc prolapse. JIACM 9: 140-142

7. Fahy UM, Oni M, Findlay D, Sell $P$ (1998) Surgical management of herniated lumbar disc in pregnancy. J Obstet Gynaecol 18: 544-545.

8. Kathirgamanathan A, Jardine AD, Levy DM, Grevitt MP (2006) Lumbar disc surgery in the third trimester--with the fetus in utero. Int J Obstet Anesth 15: $181-182$
9. Frymoyer JW, Pope MH, Costanza MC, Rosen JC, Goggin JE, et al. (1980) Epidemiologic studies of low-back pain. Spine (Phila Pa 1976) 5: 419-423.

10. American College of Radiology (ACR); Society for Pediatric Radiology (SPR) ACR-SPR practice guideline for the safe and optimal performance of fetal magnetic resonance imaging (MRI)

11. National Radiological Protection Board (1991) Principles for the protection of patients and volunteers during clinical magnetic resonance diagnostic procedures. Documents of the NRPB 2: 1

12. National Research Council (2005) Health Risks from Exposure to Low Levels of Ionizing Radiation: BEIR VII Phase 2. Washington, DC: The National Academies Press.

13. Günaydin B (2012) Gebenin gebeligi ile ilgili olmayan cerrahi girisimlerde anestezi yönetimi. Türk Anest Rean Der Dergisi 40: 1-10

14. Van de Walde M (2009) Nonobstetric surgery during pregnancy. In: Chestnut's Anesthesia Practice and Priciples (4th edn.) Pheledelphia: Mosby Elsevier. 337-360

15. Park CK (2000) The effect of patient positioning on intraabdominal pressure and blood loss in spinal surgery. Anesth Analg 91: 552-557.

16. Iyilikçi L, Erbayraktar S, Tural AN, Celik M, Sannav S (2004) Anesthetic management of lumbar discectomy in a pregnant patient. J Anesth 18: 45-47. 